\title{
The aprE leader is a determinant of extreme mRNA stability in Bacillus subtilis
}

\author{
Gustav Hambraeus, Martin Persson and Blanka Rutberg
}

\author{
1 Department of \\ Microbiology, Lund \\ University, Sölvegatan 12, \\ SE-223 62 Lund, Sweden
}

Author for correspondence: Gustav Hambraeus. Tel: +46 4622249 80. Fax: +46 46157839. e-mail: gustav.hambraeus@mikrbiol.lu.se

Keywords: mRNA secondary structure, subtilisin, amyE, stationary phase

\section{INTRODUCTION}

The steady-state amount of mRNA in a cell is a function of its rate of synthesis and its rate of decay. The half-life of bulk mRNA in growing cells of Escherichia coli is about 3-5 min, but that of specific mRNA species can vary between less than $1 \mathrm{~min}$ and more than $30 \mathrm{~min}$ (Belasco, 1993). Furthermore, the half-lives of some mRNAs vary depending on growth stage and growth conditions (Paesold \& Krause, 1999; Vytvytska et al., 1998). Thus, there exist specific mechanisms for the control of decay of various mRNA species. These mechanisms involve specific RNA-protein interactions and alternative mRNA secondary structures (Liu \& Romeo, 1997; Vytvytska et al., 1998; Yamanaka et al., 1999).

Most of our ideas about bacterial mRNA degradation are based on experiments performed with E. coli. The 5' untranslated leader of an mRNA often contains the major stability determinant(s) (Bechhofer, 1993). The rate-limiting step in mRNA degradation is thought to be an endonucleolytic cut in the $5^{\prime}$ part of the molecule, which 'opens' it for further endonucleolytic attacks towards the 3 ' end. The resulting fragments are rapidly degraded by $3^{\prime}$ to $5^{\prime}$ exoribonucleases (Spickler \& Mackie, 2000). RNase $\mathrm{E}$ is the major endoribonuclease executing the rate-limiting attack (Cohen $\& \mathrm{McD}$ owall, 1997). The general model for mRNA degradation probably applies to other bacteria but with important modifications in details. For instance, no RNase E homologue has been found in Bacillus subtilis (Kunst et al., 1997) and different patterns of degradation have been found for the same mRNA species in B. subtilis and E. coli (Persson et al., 2000).

When B. subtilis enters stationary phase, several new genetic programmes are switched on for sporulation, competence development (Lazazzera et al., 1999) or production of extracellular enzymes (Ferrari et al., 1993). The aprE gene encodes subtilisin, an extracellular proteolytic enzyme produced by stationary-phase cells (Ferrari et al., 1988). Resnekov et al. (1990) measured the decay of aprE mRNA and found it to be extremely stable in stationary-phase cells, with a half-life of at least $25 \mathrm{~min}$. This is not a general property of stationaryphase mRNA (Melin et al., 1989; Resnekov et al., 1992). Interestingly, when the bacteria were diluted into fresh medium and allowed to resume growth, the stability of aprE mRNA seemed to decrease four- to fivefold. These 
Table 1. Bacterial strains and plasmids

\begin{tabular}{|c|c|c|}
\hline & Genotype/phenotype & Source/reference \\
\hline \multicolumn{3}{|l|}{ E. coli } \\
\hline XL-1 Blue & $\begin{array}{l}\text { supE44 hsdR17 recA1 endA1 gyrA96 thi-1 relA1 } \\
\text { lac } \mathrm{F}^{\prime}\left[\text { proAB }{ }^{+} \text {lacl }{ }^{\mathrm{\alpha}} \text { lac } \mathrm{Z} \Delta \mathrm{M} 15 \operatorname{Tn} 10\left(\mathrm{Tet}^{\mathrm{R}}\right)\right]\end{array}$ & Bullock et al. (1987) \\
\hline \multicolumn{3}{|l|}{ B. subtilis } \\
\hline BR95 & ilvC1 pheA1 trpC2 & $\begin{array}{l}\text { Dept of Microbiology, Lund } \\
\text { University }\end{array}$ \\
\hline LUS1 & $\begin{array}{l}\text { BR95 with insertion of an } a p r E \text { promoter-aprE } \\
\text { leader-lacZ fusion into } a m y E ; \mathrm{Cm}^{\mathrm{R}}\end{array}$ & This work \\
\hline LUS2 & $\begin{array}{l}\text { BR95 with insertion of a } g l p D \text { promoter-aprE } \\
\text { leader-lacZ fusion into amyE; } \mathrm{Cm}^{\mathrm{R}}\end{array}$ & This work \\
\hline LUS3 & $\begin{array}{l}\text { As LUS2 but with a deletion of the first } 25 \mathrm{nt} \text { of the } \\
\text { aprE leader }\end{array}$ & This work \\
\hline LUS4 & $\begin{array}{l}\text { As LUS2 but with T substitutions at positions }+31 \\
\text { and }+32 \text { in the aprE leader }\end{array}$ & This work \\
\hline LUS5 & $\begin{array}{l}\text { BR95 with insertion of an } a m y E \text { promoter-amyE } \\
\text { leader-lacZ fusion into } t h r C ; \text { MLS }^{\mathrm{R}}\end{array}$ & This work \\
\hline LUS6 & $\begin{array}{l}\text { BR95 with insertion of a } g l p D \text { promoter-amyE } \\
\text { leader-lacZ fusion into } t h r C ; \text { MLS }^{\mathrm{R}}\end{array}$ & This work \\
\hline \multicolumn{3}{|c|}{ 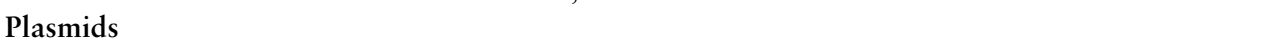 } \\
\hline pMD432 & $\mathrm{Cm}^{\mathrm{R}} \mathrm{Ap}^{\mathrm{R}} ;$ samyE::'lacZ & Dahl \& Meinhof (1994) \\
\hline pMD433 & $\mathrm{Km}^{\mathrm{R}} \mathrm{Ap}^{\mathrm{R}} ; \Delta a m y E::^{\prime} l a c Z$ & Dahl \& Meinhof (1994) \\
\hline pDG1664 & $\mathrm{MLS}^{\mathrm{R}} \mathrm{Ap}^{\mathrm{R}} ; \Delta t h r C$ & Guerout-Fleury et al. (1996) \\
\hline pLUM1041 & $\begin{array}{l}\mathrm{Km}^{\mathrm{R}} \mathrm{Ap}^{\mathrm{R}} \text {; 'lacZ ( } g l p D \text { leader from BR95 cloned in } \\
\text { front of and in-frame with lacZ in pMD433) }\end{array}$ & Glatz et al. (1998) \\
\hline pLUS1 & $\begin{array}{l}\text { Derivative of pMD432; } \triangle a m y E:: a p r E \text { promoter-aprE } \\
\text { leader-lacZ fusion }\end{array}$ & This work \\
\hline pLUS2 & $\begin{array}{l}\text { Derivative of pMD } 432 ; \Delta a m y E:: g l p D \text { promoter-aprE } \\
\text { leader-lacZ fusion }\end{array}$ & This work \\
\hline pLUS3 & $\begin{array}{l}\text { Derivative of pLUS2 with the first } 25 \mathrm{nt} \text { of the aprE } \\
\text { leader deleted }\end{array}$ & This work \\
\hline pLUS4 & $\begin{array}{l}\text { Derivative of pLUS } 2 \text { with T substitutions at }+31 \text { and } \\
+32 \text { in the aprE leader }\end{array}$ & This work \\
\hline pLUS5a & $\begin{array}{l}\text { Derivative of } \mathrm{pMD} 433 ; \triangle a m y E: \text { amyE promoter- } \\
\text { amyE leader-lacZ fusion }\end{array}$ & This work \\
\hline pLUS5b & $\begin{array}{l}\text { Derivative of pDG1664; } \Delta t h r C:: a m y E \text { promoter- } \\
\text { amyE leader-lacZ fusion }\end{array}$ & This work \\
\hline pLUS6a & $\begin{array}{l}\text { Derivative of } \mathrm{pMD} 433 ; \Delta a m y E:: g l p D \text { promoter- } \\
\text { amyE leader-lacZ fusion }\end{array}$ & This work \\
\hline pLUS6b & $\begin{array}{l}\text { Derivative of pDG1664; } \Delta t h r C:: g l p D \text { promoter- } \\
\text { amyE leader-lacZ fusion }\end{array}$ & This work \\
\hline
\end{tabular}

findings indicated the presence of a specific control mechanism for decay of aprE mRNA related to growth phase and perhaps operating also on mRNA for other extracellular enzymes whose synthesis is induced in stationary-phase cells.

In the present work we re-examined the results of Resnekov et al. (1990) with the primary aim of identifying a possible control mechanism for growth-stagedependent differential rate of decay of aprE mRNA. However, we found that aprE mRNA has the same extreme stability in both stationary-phase and growing cells. The apparent growth-stage-dependent stability of aprE mRNA can be fully explained by the techniques used by Resnekov et al. (1990). Our experiments also demonstrate that the determinant(s) for the extreme stability of aprE mRNA is contained within the leader.

\section{METHODS}

Bacteria, plasmids and primers. Bacteria and plasmids are listed in Table 1 and primers in Table 2.

Growth of bacteria. Bacteria were kept on TBAB plates. E. coli was grown in LB. B. subtilis was grown in NSMP (Fortnagel \& Freese, 1968) at $37^{\circ} \mathrm{C}$ on a rotary shaker at 200 r.p.m. Antibiotics were added to the following concentrations: chloramphenicol, $5 \mathrm{mg} \mathrm{l}^{-1}$; erythromycin, 
Table 2. Primers

\begin{tabular}{|ll|}
\hline \multicolumn{1}{|c}{ Name } & \\
\hline aprEBam1 & GTT GGA TCC AGT CTC TAC GGA AAT AGC GAG \\
aprEBam2 & CAA GGA TCC GAT CCA CAA TTT TTT GCT TCTC \\
aprEconst & TTG GAT CCT TTT AAA TAA AGT AAT ACT ATG GTA TAA TGG \\
& TTA CAC AGA ATA GTC TTT TAA GTA AGT CTA CTC TG \\
aprEconstS & TTG GAT CCT TTT AAA TAA AGT AAT ACT \\
aprEdel25 & GGT ATA ATG GTT ACA CTC TGA ATT TT \\
aprEdel25inv & AAA ATT CAG AGT GTA ACC ATT ATA CC \\
aprEsubTT & AGT CTA CTC TTT ATT TTT TTA AAA GG \\
aprEsubTTinv & CCT TTT AAA AAA ATA AAG AGT AGA CT \\
amyE1 & ATG TTT GCA AAA CGA TTC AAA ACC \\
amyESeq & CGA CGG TGC TGT AAG CTC ATT CGA \\
lacZ60 & CGC CAG CTG GCG AAA GGG GG \\
amyEBam1 & GAG GGA TCC GTT CAC AGT TTC GGG \\
amyEBam2 & GGT TTT GGA TCC TTT TGC AAA CAT TC \\
amyEHindII & GCG AAG CTT ATC CGT TCA CAG TTT CGG G \\
amyEconst & TTG GAT CCT TTT AAA TAA AGT AAT ACT ATG GTA TAA TGG \\
TamyEconstS & TTA CAA GCG TTA ACA AAA TTC TCC AGT CTT CAC ATC GG \\
lacZHindIII & GAA TAA AGC TTT AAA TAA AGT AAT ACT ATGG \\
glpDBam1 & CTG TGG GAT CCT GGA TCC TGG AAG GAC C \\
lacZseq & GTT TTC CCA GTC ACG ACG TTG \\
\hline
\end{tabular}

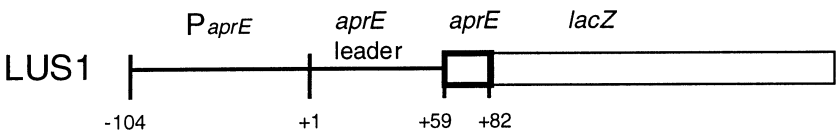

LUS2

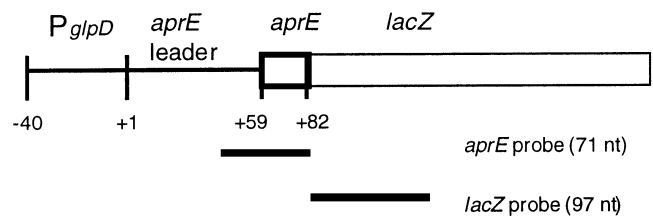

Fig. 1. Schematic representation of the inserts of $B$. subtilis LUS1 and LUS2. The aprE promoter and leader and part of the aprE coding region from BR95 were amplified by PCR and cloned in-frame with lacZ in pMD432. The aprE promoter-aprE leader-lacZ fusion was integrated into the chromosome of BR95 at the amyE gene to give LUS1. In LUS2, the aprE promoter was substituted with the $g / p D$ promoter. +1 indicates the transcription start point. The thick lines below the constructs illustrate the probes used to detect aprE and lacZ mRNAs, respectively.

$0.5 \mathrm{mg} \mathrm{l}^{-1}$; lincomycin, $12.5 \mathrm{mg} \mathrm{l}^{-1}$; ampicillin, $50 \mathrm{mg} \mathrm{l}^{-1}$; rifampicin, $100 \mathrm{mg} \mathrm{l}^{-1}$.

Genetic techniques. B. subtilis was grown to competence as described by Arwert \& Venema (1973). E. coli was made competent as described by Mandel \& Higa (1970).

Enzyme activities. $\beta$-Galactosidase activity was detected on TBAB plates containing $40 \mathrm{mg} \mathrm{X-Gal} \mathrm{l^{-1 }}$. $\beta$-Galactosidase activity in liquid cultures was assayed according to Miller (1972) as described by Glatz et al. (1998). Amylase activity was detected on $\mathrm{TBAB}$ plates containing $1.5 \%$ starch. After incubation for $2 \mathrm{~d}$, the plates were sprayed with an iodine solution $(1 \mathrm{~g}$ iodine and $2 \mathrm{~g}$ potassium iodide in $300 \mathrm{ml}$ distilled water). A clear halo is observed around amylasepositive colonies.

Construction of strains. A sequence containing the aprE promoter, leader sequence and the first 8 codons of the aprE gene, from -104 to +82 (Ferrari et al., 1988) was amplified from chromosomal DNA of B. subtilis BR95 with PCR using primers aprEBam1 and aprEBam2. The fragment was cleaved at both ends by restriction enzyme Bam $\mathrm{HI}$ and ligated into the BamHI site of the B. subtilis integration plasmid pMD432. Competent E. coli XL-1 Blue was transformed with the ligate with selection for ampicillin resistance. Transformants producing $\beta$-galactosidase were identified on X-Gal plates, and from one of these, pLUS1 was purified and the inserted fragment was sequenced. pLUS1 was then used to transform B. subtilis BR95, with selection for chloramphenicol resistance. Transformants producing $\beta$-galactosidase and lacking amylase activity were isolated. One of these was kept and the strain was named LUS1 (Fig. 1).

From plasmid pLUS1, the region containing the transcribed aprE part $(+1$ to +82$)$ was amplified with PCR using primers aprEconst and aprEBam2. aprEconst substitutes the aprE promoter with the $g l p D$ promoter $(-40$ to -1$)$ (Holmberg $\&$ Rutberg, 1992). After cleavage with BamHI, the amplified fragment was ligated to BamHI-cleaved pMD432. Competent E. coli XL-1 Blue was transformed with the ligate, with selection for ampicillin resistance. Transformants producing $\beta$-galactosidase were identified on X-Gal plates and from one of these, pLUS2 was purified and the inserted fragment was sequenced. pLUS2 was then used to transform B. subtilis BR95 and transformants were isolated as described above. The resultant strain was named LUS2 (Fig. 1).

Plasmid pLUS2 was used to construct two additional strains with modifications in the aprE leader sequence by running 
PCRs with modified primers. A first PCR was run with primers aprEconstS and aprEdel25inv in one mix and aprEdel 25 and aprEBam 2 in another. aprEdel25inv and aprEdel 25 are complementary to each other and introduce a deletion of $25 \mathrm{nt}$. The two fragments obtained were mixed and a second PCR was run with primers aprEconstS and aprEBam2. The fragment obtained was ligated to BamHIcleaved pMD432 and E. coli XL-1 Blue was transformed with the ligate. Ampicillin-resistant transformants were selected and pLUS3 was isolated from one of these. pLUS4 was obtained analogously but with the primers aprEdel $25 \mathrm{inv}$ and aprEdel25 replaced with the primers aprEsubTTinv and aprEsubTT. These primers introduce $\mathrm{T}$ substitutions at +31 and +32 . pLUS3 and pLUS4 were used to transform B. subtilis BR95, with selection for chloramphenicol resistance. Transformants were isolated and the resultant strains were named LUS3 and LUS4.

A sequence containing the $a m y E$ promoter, leader and part of the coding region, from -100 to +134 (Nicholson \& Chambliss, 1986), was amplified by PCR with primers amyEBam1 and amyEBam2. The fragment was cleaved with Bam HI and ligated to BamHI-cleaved pMD433. E. coli XL-1 Blue was transformed with the ligate, selecting for ampicillin resistance. Plasmid pLUS5a was isolated from one of the transformants. From pLUS5a, the region containing the transcribed amyE part $(+1$ to +134$)$ was amplified with PCR using primers amyEconst and amyEBam2. amyEconst substitutes the amyE promoter with the $g l p D$ promoter $(-40$ to -1) (Holmberg \& Rutberg, 1992). After cleavage with $B a m \mathrm{HI}$, the amplified fragment was ligated to BamHI-cleaved pMD433. Competent E. coli XL-1 Blue was transformed with the ligate, with selection for ampicillin resistance. Transformants producing $\beta$-galactosidase were identified on X-Gal plates and from one of these, pLUS6a was purified.

pLUS5a and pLUS6a were used as templates for PCRs with primer pairs amyEHindIII/lacZHindIII and amyEconstS/ lacZHindIII, respectively. After cleavage with HindIII, the fragments were ligated to HindIII-cleaved pDG1664. E. coli XL-1 Blue was transformed with the ligates, selecting for ampicillin resistance. pLUS5b and pLUS6b were isolated and used to transform B. subtilis BR95. Transformants resistant to erythromycin and lincomycin $\left(M_{L} S^{\mathrm{R}}\right)$ were selected and from each transformation a transformant that produced $\beta$-galactosidase and required threonine for growth was kept. The resultant strains were named LUS5 and LUS6, respectively.

RNA techniques. Total RNA was extracted from B. subtilis as described by Resnekov et al. (1990). For measuring mRNA half-lives, rifampicin $\left(100 \mathrm{mg} \mathrm{l}^{-1}\right)$ was added and samples were then removed at intervals for extraction of total RNA. Electrophoresis of RNA for Northern blots was done as described by Thomas (1980), and the RNA was then blotted onto Hybond-N filters (Amersham). Twenty micrograms of RNA was added to each well unless otherwise indicated. Single-stranded (ss) DNA probes were generated as described before (Persson et al., 2000) with the following primers: lacZ60 for $l a c Z$ constructs, aprEBam 2 for $a p r E$, and amyESeq for $a m y E$. To generate templates for the ssPCR, specific fragments were amplified with PCR using the following primers and templates: glpDBam1 and lacZ60 with pLUM1041, aprESubTT and aprEBam2 with pLUS1, and amyE1 and amyESeq with chromosomal B. subtilis DNA. The glpDBam1-lacZ60 fragment was cleaved with BamHI and the lac $Z$ part was isolated prior to the ssPCR. After hybridization, the radioactivity of the bands was quantified with a PhosphorImager (Molecular Dynamics). 23S rRNA and 16S rRNA were used as size markers. Primer extension analysis was performed according to the method of Ayer \& Dynan (1988). The primer used was lacZseq.

\section{RESULTS}

\section{Construction and transcriptional control of aprE-lacZ fusions}

A fusion was made between the aprE promoter, leader and the first eight codons of aprE ( -104 to +82$)$ (Park et al., 1989) and the coding region of E. coli lacZ (Fig. 1). The fusion was inserted into the amyE locus of $B$. subtilis BR95. The resulting strain was named LUS1. A second fusion was made in which the aprE promoter region was substituted with the constitutive $B$. subtilis glpD promoter ( -40 to -1 ) (Fig. 1). The fusion was inserted into the amyE locus in B. subtilis BR95 to give strain LUS2. The identity of the fusions was verified by DNA sequencing and the transcriptional start site $(+1)$ was verified by primer extension experiments.

LUS1 and LUS2 were grown as described in Methods. At different times, samples were taken for measurement of $\mathrm{OD}_{600}$ and $\beta$-galactosidase activity. In LUS1, $\beta$-galactosidase activity was detected only after the cells had entered stationary phase, whereas in LUS2, $\beta$-galactosidase was produced throughout exponential growth (Fig. 2). These results are in good agreement with the fact that a major control of aprE expression occurs at initiation of transcription through the $\mathrm{AbrB} / \mathrm{SpoOA}$ switch (Olmos et al., 1996).

\section{The aprE leader is a determinant of extreme mRNA stability}

LUS1 was grown to $t=1.5$, i.e. for $1.5 \mathrm{~h}$ past the entry into stationary phase, at which time rifampicin (100 $\mathrm{mg} \mathrm{l}^{-1}$ ) was added to the culture. RNA was extracted at different times thereafter. The relative amounts of aprE and aprE-lacZ transcripts were de-

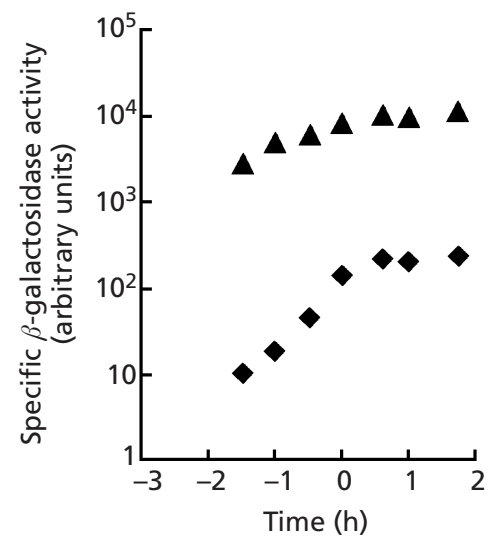

Fig. 2. $\beta$-Galactosidase activities of LUS1 $(\boldsymbol{\bullet})$ and LUS2 ( $\boldsymbol{\Delta})$. The bacteria were grown in NSMP at $37{ }^{\circ} \mathrm{C}$ on a rotary shaker at 200 r.p.m. and $\beta$-galactosidase activities were measured at intervals. $t=0$ is the time of entry into stationary phase. The results are from three individual experiments. 
(a)

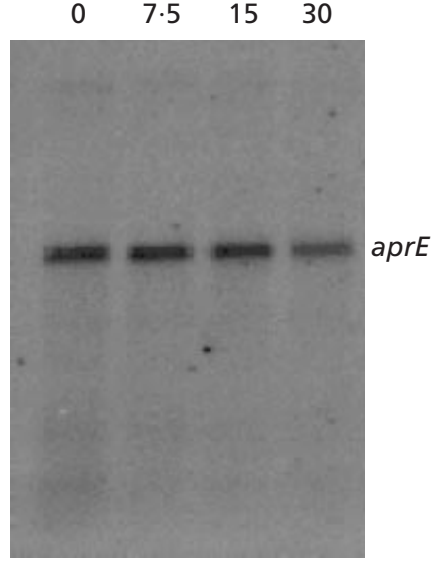

(b)

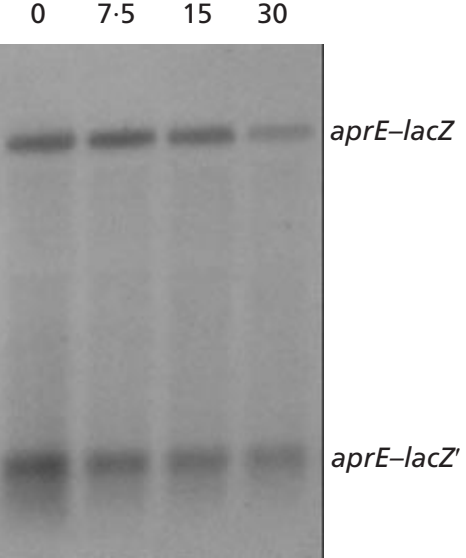

(c)

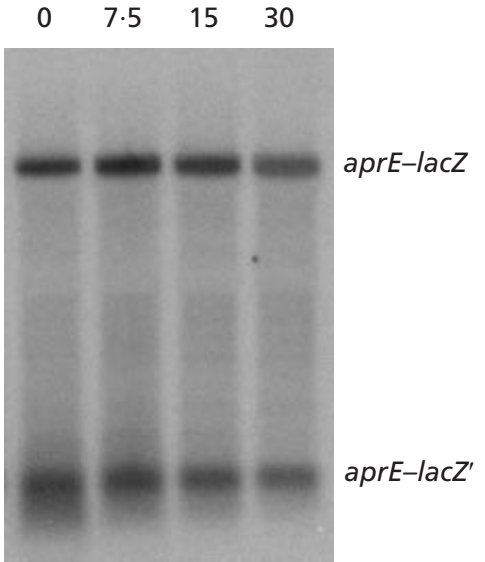

Fig. 3. Northern blot analysis of (a) the native aprE transcript of LUS1; (b) the aprE promoter-aprE leader-lacZ transcript of LUS1; (c) the glpD promoter-aprE leader-lacZ transcript of LUS2. The bacteria were grown to $t=1.5$ and RNA was extracted at $0 \mathrm{~min}$ and at 7.5, 15 and $30 \mathrm{~min}$ after the addition of rifampicin. The experiments were repeated at least three times with similar results.
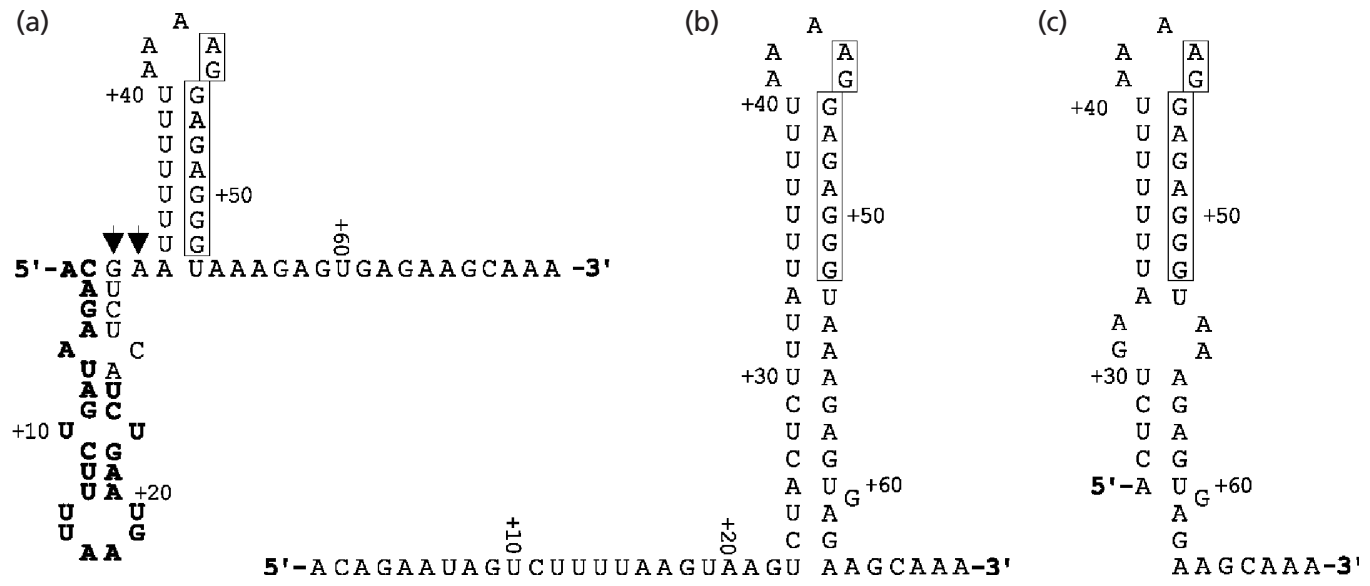

Fig. 4. Predicted secondary structures of the aprE leader in (a) LUS2, (b) LUS4, and (c) LUS3. In (a), the substitution of 2 nt in LUS4 is marked with arrows and the deleted $25 \mathrm{nt}$ in LUS3 are bold-faced. The boxed nucleotides represent the RBS. The free energies of the secondary structures are for (a) $-44.8 \mathrm{~kJ}(-37.7 \mathrm{~kJ}$ for the first and $-7 \cdot 1 \mathrm{~kJ}$ for the second stem-loop); (b) $-65.3 \mathrm{~kJ}$; (c) $-33.6 \mathrm{~kJ}$ (http://mfold.wustl.edu/ folder/rna/form1.cgi).

termined in Northern blots using probes specific for $a p r E$ and $l a c Z$. The half-lives of the two transcripts were similar and at least $25 \mathrm{~min}$ (Fig. 3a, b). These results indicate that the aprE leader determines the stability of both transcripts and that sequences downstream of +82 in the aprE gene have little effect on mRNA stability. The rate of decay of the above two transcripts was also determined by primer extension analysis using a primer specific for the lac $Z$ part of the aprE-lacZ transcript. The results of these experiments were essentially identical to those obtained with Northern blots (data not shown).

The decay of the aprE-lacZ transcript in stationaryphase cells was next measured in LUS2, in which the aprE promoter is replaced by the $g l p D$ promoter. Again, a half-life longer than 25 min was observed, indicating that the rate of degradation of the aprE transcript is not affected by sequences upstream of $a p r E+1$ (Fig. 3c).

A truncated transcript of about $700 \mathrm{nt}$ was seen in the Northern blots for strains LUS1 and LUS2 (Fig. 3b, c). This represents the $5^{\prime}$ part of the full-length transcript and has been found also in other types of transcriptionaltranslational fusions with lacZ in B. subtilis (Persson et al., 2000). The truncated transcript decayed at the same rate as the full-length transcript, which further supports the notion that the aprE leader is the major stability determinant also in the fusion transcript.

To examine how changes in the aprE leader transcript would affect mRNA stability, two modifications were introduced into the aprE leader of the lacZ fusion in LUS2. These were chosen so as to significantly alter the secondary structure of the leader (Fig. 4). Prediction of 


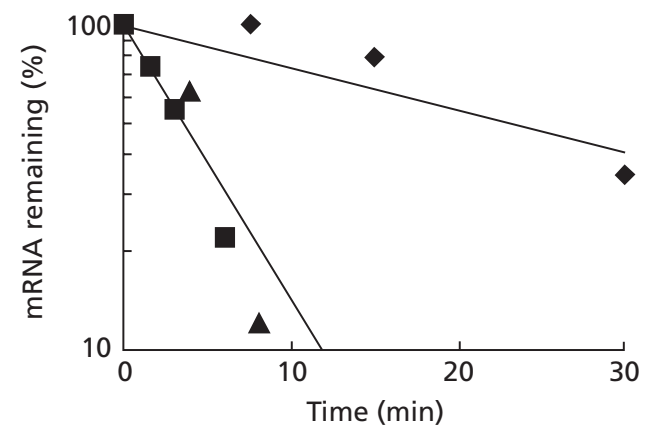

Fig. 5. Half-lives calculated from Northern blots of aprE-lacZ fusion transcripts from LUS2 $(\diamond)$, LUS3 $(\boldsymbol{\Delta})$ and LUS4 $(\boldsymbol{\square})$. The bacteria were grown to $t=1.5$ and RNA was extracted at 0 min and at different times after the addition of rifampicin. The experiments were repeated at least twice with similar results.

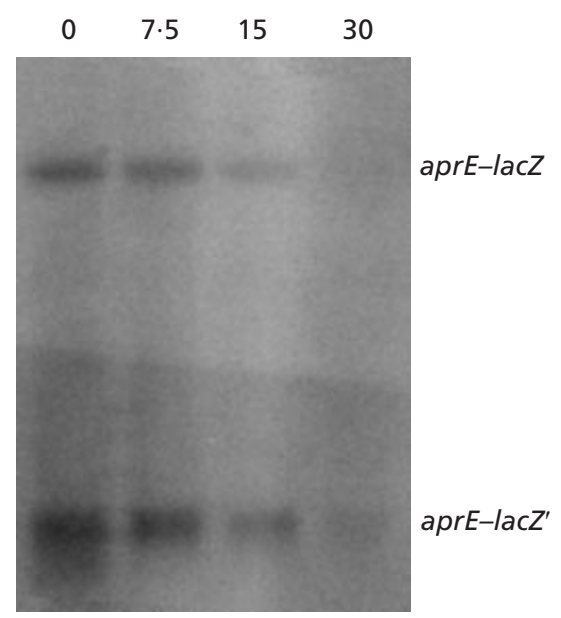

Fig. 6. Northern blots showing steady-state levels of the aprE promoter-aprE leader-lacZ transcript of LUS1 after a shift-up. The bacteria were grown to $t=1.5$ and were then diluted into fresh, prewarmed medium to $\mathrm{OD}_{600} 0.5$. Samples were taken at 0 min and at 7.5, 15 and $30 \mathrm{~min}$ after dilution and RNA was extracted. The experiment was repeated twice with similar results.

secondary structures is very uncertain. Alternative structures are often suggested with similar free energies. One modification was a deletion of nucleotides +1 to +25 , resulting in strain LUS3. In the second modification, $\mathrm{a} G$ and an A residue, at positions +31 and +32 , respectively, were exchanged for two $T$ residues, resulting in strain LUS4. According to computer-predicted folding (Zuker, 1989), the RBS of both LUS3 and LUS4 leader is contained within a strong stem-loop structure (Fig. 4b, c). In LUS3, the stem-loop is located at the very $5^{\prime}$ end and in LUS4, 22 unpaired bases precede the stem-loop.

LUS3 and LUS4 were grown to $t=1 \cdot 5$, at which time rifampicin was added to the cultures. RNA was ex-

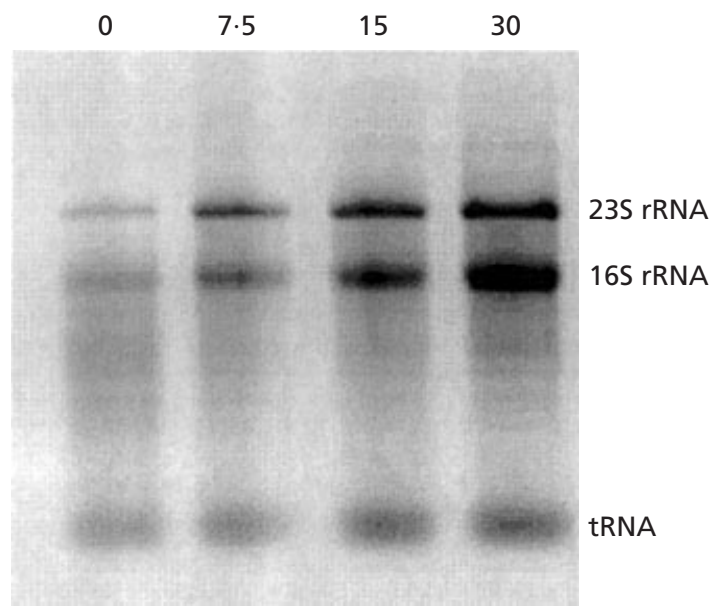

Fig. 7. An agarose ethidium bromide gel, showing increase of rRNA in $B$. subtilis after a shift-up. The bacteria were grown to $t=1.5$ and were then diluted into fresh prewarmed medium to $\mathrm{OD}_{600} 0.5$. Samples were taken at intervals during $30 \mathrm{~min}$ after dilution, at which time the cells were growing exponentially. Total RNA was extracted. Each lane contained RNA from $1.25 \mathrm{ml}$ bacterial culture. Bands were quantified using Kodak Digital Science 1D Image Analysis Software.

tracted at different times and Northern blots were performed. The modifications in LUS3 and LUS4 destabilized the aprE-lac $Z$ transcript, giving a half-life of 5-6 min (Fig. 5).

\section{The extreme stability of aprE mRNA does not change with growth stage}

Resnekov et al. (1990) reported that when a B. subtilis culture in early stationary phase was diluted into fresh medium, the steady-state level of aprE mRNA rapidly declined. This finding was interpreted as being due to a growth-stage-related destabilization of aprE mRNA. We have repeated and confirmed these results (Fig. 6). However, the relative rate of synthesis of rRNA rapidly increases following dilution. In Fig. 7 it is seen that the amount of rRNA increased about threefold within 30 min after a shift-up. This is in accordance with the classical observations made with E. coli following a growth shift-up (Bremer \& Dennis, 1996). Thus, a rapid decline of aprE mRNA upon dilution into fresh medium could reflect a rapid dilution of this mRNA in the total RNA pool rather than accelerated degradation. To determine the half-life of $a p r E$ mRNA at various times after dilution is difficult because transcription from the aprE promoter is rapidly shut off. However, the half-life of the aprE-lacZ fusion transcript produced from the constitutive $g l p D$ promoter can readily be determined after dilution of stationary-phase cells into fresh medium as well as in exponentially growing cells. The results of such experiments using strain LUS2 show that even 30 min after dilution into fresh medium, when growth has well resumed, the aprE-lacZ mRNA is still ex- 


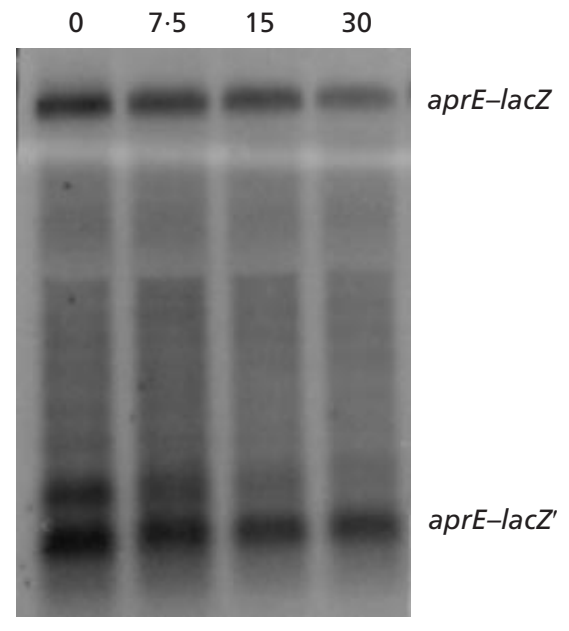

Fig. 8. Northern blot analysis of the $g / p D$ promoter-aprE leader-lacZ transcript of LUS2. The bacteria were grown to $t=$ 1.5 and were then diluted into fresh, prewarmed medium to $\mathrm{OD}_{600} 0 \cdot 5$. Rifampicin was added $30 \mathrm{~min}$ after dilution. RNA was extracted at 0 min and at 7.5, 15 and 30 min after the addition of rifampicin. The experiment was repeated three times with similar results.

tremely stable, with a half-life of at least 25 min (Fig. 8). Similarly, in an exponentially growing culture of LUS2 started from a small inoculum, aprE-lacZ mRNA halflife is well above $25 \mathrm{~min}$ (data not shown).

\section{Half-life of amyE mRNA and properties of amyE-lacZ fusions}

The aprE gene is one of a number of B. subtilis genes that code for secreted proteins which are synthesized after growth has stopped and which are under (partly) common transcriptional control (Ferrari et al., 1993). Another well-studied gene in this category is amyE, which encodes $\alpha$-amylase. The half-life of amyE mRNA was measured in B. subtilis in early stationary phase and determined to be about 5 min (Fig. 9), i.e. similar to that of bulk B. subtilis mRNA. To compare the properties of the fusion transcripts with those of the native amyE transcript, a fusion between the amyE promoter region, the $a m y E$ leader and $l a c Z$ was made analogously to the previously described fusion involving aprE. The fusion was inserted into the $B$. subtilis thrC gene to give strain LUS5. LUS5 was grown in NSMP and at different points, samples were taken for determination of $\beta$-galactosidase activity. The activity was very low during growth and increased fivefold as the cells entered stationary phase (data not shown). These results confirm that expression of the amyE-lacZ fusion is under the same temporal control as the amyE gene itself.

To measure the half-life of the amyE-lacZ fusion transcript, we constructed LUS6, in which the tightly controlled amyE promoter is replaced by the constitutive $g l p D$ promoter. LUS6 was grown in NSMP to early stationary phase, at which time rifampicin was added to

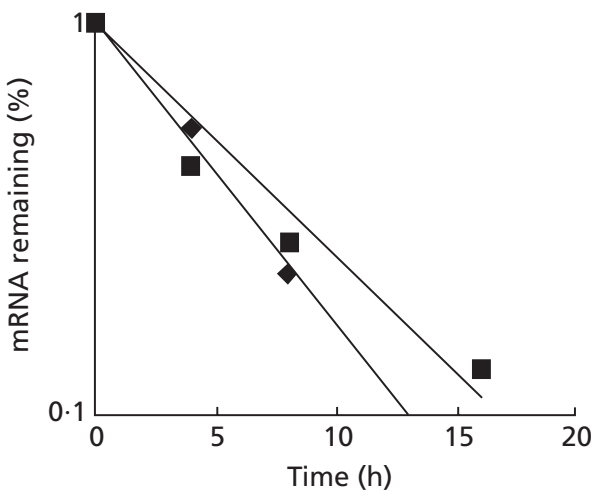

Fig. 9. Half-lives calculated from Northern blot analysis of the native amyE transcript of LUS $5(\diamond)$ and the amyE-lacZ transcript of LUS6 ( $\boldsymbol{\square}$ ). The bacteria were grown to $t=1.5$ and RNA was extracted at $0 \mathrm{~min}$ and at 4, 8 and $16 \mathrm{~min}$ after the addition of rifampicin. The experiments were repeated twice with similar results.

the culture. Total RNA was extracted at different times and the relative amounts of amyE-lacZ transcript were determined in Northern blots using a probe specific for lacZ. The half-life of the amyE-lacZ fusion transcript was similar to that of the native amyE transcript, i.e. about 5 min (Fig. 9). This demonstrates that the amyE leader is a major determinant of amyE mRNA stability and also shows the general validity of using fusion transcripts for comparisons of rates of mRNA decay.

\section{DISCUSSION}

B. subtilis aprE mRNA has been shown previously to be extremely stable in stationary-phase cells, with a halflife of at least $25 \mathrm{~min}$ (Resnekov et al., 1990); the present work confirms this finding. Furthermore, in that earlier paper, experiments were presented which were interpreted to show that in growing cells, the rate of degradation of aprE mRNA was increased four- to fivefold, indicating that the stability of this mRNA was regulated by growth stage. In growing cells, the aprE promoter is effectively shut off, which complicates measurements of the decay of the aprE transcript in a growth-shift experiment. To circumvent this problem, decay of aprE mRNA was measured as decay of the steady-state amount of the transcript at various times after a shift from stationary phase to growth.

In the present work we have shown that the determinant(s) for the extreme stability of aprE mRNA is located in the $5^{\prime}$ leader. A transcript of a transcriptionaltranslational fusion between the aprE leader and E. coli lacZ was found to have the same stability as the native $a p r E$ transcript. Furthermore, substituting the aprE promoter with the constitutive B. subtilis $g l p D$ promoter had no effect on the rate of decay of the fusion transcript. By using the $g l p D$ promoter one can directly measure the rate of decay of the aprE-lacZ fusion transcript (or the aprE transcript) in growing and stationary-phase cells. 
The results of such measurements show that the half-life of the aprE-lacZ fusion transcript is at least $25 \mathrm{~min}$ under all conditions tested. Thus, contrary to previous suggestions (Resnekov et al., 1990) there is no growthstage-related control of aprE mRNA stability. The increased rate of degradation of aprE mRNA on shift-up observed by Resnekov et al. (1990) is spurious. The shift-up is immediately followed by a selective increase in stable RNA whereas the aprE promoter is turned off. In experiments of Resnekov et al. (1990) this leads to an apparent increase in degradation rate of aprE mRNA which is simply due to a dilution effect.

There are few data available which compare the stability of a specific $B$. subtilis mRNA at different growth stages, but increased stability is not a general property of stationary-phase mRNA (Melin et al., 1989). In the present work we have also determined the half-life of amyE mRNA, which encodes another stationary-phasespecific $B$. subtilis exoenzyme, to be $5 \mathrm{~min}$. This shows that extreme stability is not a general property of exoenzyme transcripts. Whatever the physiological reason for the exceptionally high stability of the aprE mRNA, it contributes to a high level of production of subtilisin in the 'stationary-phase window' where the aprE promoter is active.

Very few bacterial transcripts of extreme stability have been characterized, erm $C$ and $g s i B$ being two of the bestknown examples in B. subtilis. The half-life of the ermC transcript increases about 20-fold upon exposure of the bacteria to erythromycin (Bechhofer \& Zen, 1989). Binding of the drug to ribosomes translating a short ORF preceding the coding region for the ErmC protein stalls the ribosomes at this ORF. The stalling protects the whole erm $C$ transcript from degradation, possibly by shielding a nuclease-sensitive site and/or affecting the secondary structure of the transcript. The gsiB transcript, which is produced from a SigB-dependent promoter and encodes a stress-related protein, has a halflife of at least $20 \mathrm{~min}$ (Jurgen et al., 1998). The gsiB gene has a very strong RBS with an optimal spacing to the AUG start codon. Mutations that weaken the gsiB RBS lead to a decrease in the half-life of the transcript, suggesting that a major factor in determining the gsiB mRNA half-life is the interaction between the RBS and $16 \mathrm{~S}$ rRNA. However, RBS mutations also lead to some changes in the predicted secondary structure of the $g s i B$ mRNA leader sequence, which complicates the interpretation of these experiments.

The free energy of binding of the RBS and the $3^{\prime}$ end of $16 \mathrm{~S}$ rRNA is very similar for $g s i B$, aprE and $a m y E$ (Tinoco et al., 1973) and yet the amyE transcript decays at least five times faster than those of the other two genes. It should be noted that the start codon is AUG for $g s i B$ and amyE but GUG for aprE. Thus, a model suggesting the RBS-16S rRNA interaction to be a major determinant for mRNA stability is hardly of general validity. However, the interaction between $16 \mathrm{~S}$ rRNA and the mRNA leader in forming the initiation complex is a function not only of base complementarity but also of the secondary structure of the leader (Yamanaka et al., 1999). The favoured predicted secondary structure of the wild-type aprE leader is a stem-loop at the very 5' end with the RBS contained in a region with weak interactions (Fig. 4a). The computer prediction also suggests an alternative structure with similar free energy. However, the formation of this structure involves opening the already folded stem-loops shown in Fig. 4(a). That makes this alternative structure less likely. Changing two bases in the leader (G31 and A32 both changed to T) leads to a large structural change with a perfect stem-loop containing the RBS and preceded by 22 unpaired bases (Fig. 4b). This transcript has a halflife of about $5 \mathrm{~min}$. The same stem-loop was obtained by deleting $25 \mathrm{nt}$ in the leader (Fig. 4c). Also this modification led to a major destabilization of the transcript. Deleting a single-stranded $5^{\prime}$ end is known to stabilize some E. coli transcripts (Emory et al., 1992).

Clearly, the secondary structure of the aprE transcript is important for the extreme stability of aprE mRNA. This may simply depend on occlusion of RNase-sensitive sites, but other factors may also be involved, e.g. specific (temporary or permanent) binding of proteins to the transcript. This is a known mechanism for stabilizing or destabilizing transcripts. For example, B. subtilis glpD mRNA can be stabilized by the GlpP antiterminator protein (Glatz et al., 1996) and in E. coli, the ompA and $g \operatorname{lgC}$ transcripts are destabilized by the Hfq and CsrA proteins, respectively (Vytvytska et al., 1998, Liu \& Romeo, 1997). Finally, we wish to point out that there are striking sequence similarities between the sequence around the aprE RBS and that of a polypurine-rich sequence in bacteriophage SP82 which functions as a $5^{\prime}$ stabilizer in B. subtilis (Hue et al., 1995).

\section{ACKNOWLEDGEMENTS}

This project was supported by grants from Kungliga Fysiografiska Sällskapet $\mathrm{i}$ Lund and the Emil and Wera Cornell Foundation. We thank Lars Rutberg for valuable discussions and Claes von Wachenfeldt for critically reading the manuscript.

\section{REFERENCES}

Arwert, F. \& Venema, G. (1973). Transformation in Bacillus subtilis. Fate of newly introduced transforming DNA. Mol Gen Genet 123, 185-198.

Ayer, D. E. \& Dynan, W. S. (1988). Simian virus 40 major late promoter: a novel tripartite structure that includes intragenic sequences. Mol Cell Biol 8, 2021-2033.

Bechhofer, D. H. (1993). 5' mRNA stabilizers. In Control of Messenger RNA Stability, pp. 31-52. Edited by J. G. Belasco \& G. Brawerman. San Diego: Academic Press.

Bechhofer, D. H. \& Zen, K. H. (1989). Mechanism of erythromycininduced erm C mRNA stability in Bacillus subtilis. J Bacteriol 171, 5803-5811.

Belasco, J. G. (1993). mRNA degradation in prokaryotic cells : an overview. In Control of Messenger RNA Stability, pp. 3-12. Edited by J. G. Belasco \& G. Brawerman. San Diego: Academic Press. 
Bremer, H. \& Dennis, P. P. (1996). Modulation of chemical composition and other parameters of the cell by growth stage. In Escherichia coli and Salmonella: Cellular and Molecular Biology, pp. 1553-1570. Edited by F. C. Neidhardt and others. Washington, DC: American Society for Microbiology.

Bullock, W. O., Fernandez, J. M. \& Short, J. M. (1987). XL1-Blue: a high efficiency plasmid transforming RecA Escherichia coli strain with beta-galactosidase selection. Biotechniques 5, 376378.

Cohen, S. N. \& McDowall, K. J. (1997). RNase E: still a wonderfully mysterious enzyme. Mol Microbiol 23, 1099-1106.

Dahl, M. K. \& Meinhof, C. G. (1994). A series of integrative plasmids for Bacillus subtilis containing unique cloning sites in all three open reading frames for translational lacZ fusions. Gene 145, 151-152.

Emory, S. A., Bouvet, P. \& Belasco, J. G. (1992). A 5'-terminal stem-loop structure can stabilize mRNA in Escherichia coli. Genes Dev 6, 135-148.

Ferrari, E., Henner, D. J., Perego, M. \& Hoch, J. A. (1988). Transcription of Bacillus subtilis subtilisin and expression of subtilisin in sporulation mutants. J Bacteriol 170, 289-295.

Ferrari, E., Jarnagin, A. S. \& Schmidt, B. F. (1993). Commercial production of extracellular enzymes. In Bacillus subtilis and Other Gram-positive Bacteria: Biochemistry, Physiology, and Molecular Genetics, pp. 917-937. Edited by A. L. Sonenshein, J. A. Hoch \& R. Losick. Washington, DC: American Society for Microbiology.

Fortnagel, P. \& Freese, E. (1968). Analysis of sporulation mutants. II. Mutants blocked in the citric acid cycle. J Bacteriol 95, 1431-1438.

Glatz, E., Nilsson, R. P., Rutberg, L. \& Rutberg, B. (1996). A dual role for the Bacillus subtilis glpD leader and the GlpP protein in the regulated expression of $g l p D$ : antitermination and control of mRNA stability. Mol Microbiol 19, 319-328.

Glatz, E., Persson, M. \& Rutberg, B. (1998). Antiterminator protein GlpP of Bacillus subtilis binds to glpD leader mRNA. Microbiology 144, 449-456.

Guerout-Fleury, A. M., Frandsen, N. \& Stragier, P. (1996). Plasmids for ectopic integration in Bacillus subtilis. Gene 180, 57-61.

Holmberg, C. \& Rutberg, L. (1992). An inverted repeat preceding the Bacillus subtilis glpD gene is a conditional terminator of transcription. Mol Microbiol 6, 2931-2938.

Hue, K. K., Cohen, S. D. \& Bechhofer, D. H. (1995). A polypurine sequence that acts as a $5^{\prime}$ mRNA stabilizer in Bacillus subtilis. $J$ Bacteriol 177, 3465-3471.

Jurgen, B., Schweder, T. \& Hecker, M. (1998). The stability of mRNA from the $g s i B$ gene of Bacillus subtilis is dependent on the presence of a strong ribosome binding site. Mol Gen Genet 258, 538-545.

Kunst, F., Ogasawara, N., Moszer, I. \& 148 other authors (1997). The complete genome sequence of the gram-positive bacterium Bacillus subtilis. Nature 390, 249-256.

Lazazzera, B. A., Palmer, T., Quisel, J. \& Grossman, A. D. (1999). Cell density control of gene expression and development in Bacillus subtilis. In Cell-Cell Signaling in Bacteria, pp. 27-46. Edited by G. M. Dunny \& S. A. Winans. Washington, DC: American Society for Microbiology.
Liu, M. Y. \& Romeo, T. (1997). The global regulator CsrA of Escherichia coli is a specific mRNA-binding protein. J Bacteriol 179, 4639-4642.

Mandel, M. \& Higa, A. (1970). Calcium-dependent bacteriophage DNA infection. J Mol Biol 53, 159-162.

Melin, L., Rutberg, L. \& von Gabain, A. (1989). Transcriptional and posttranscriptional control of the Bacillus subtilis succinate dehydrogenase operon. J Bacteriol 171, 2110-2115.

Miller, J. (1972). Experiments in Molecular Genetics. Cold Spring Harbor, NY: Cold Spring Harbor Laboratory.

Nicholson, W. L. \& Chambliss, G. H. (1986). Molecular cloning of cis-acting regulatory alleles of the Bacillus subtilis amyR region by using gene conversion transformation. J Bacteriol 165, 663-670.

Olmos, J., Bolanos, V., Causey, S., Ferrari, E., Bollvar, F. \& Valle, F. (1996). A functional Spo0A is required for maximal aprE expression in Bacillus subtilis. FEBS Lett 381, 29-31.

Paesold, G. \& Krause, M. (1999). Analysis of $r p o S$ mRNA in Salmonella dublin: identification of multiple transcripts with growth-phase-dependent variation in transcript stability. $J$ Bacteriol 181, 1264-1268.

Park, S. S., Wong, S. L., Wang, L. F. \& Doi, R. H. (1989). Bacillus subtilis subtilisin gene (aprE) is expressed from a sigma A (sigma 43) promoter in vitro and in vivo. J Bacteriol 171, 2657-2665.

Persson, M., Glatz, E. \& Rutberg, B. (2000). Different processing of an mRNA species in Bacillus subtilis and Escherichia coli. J Bacteriol 182, 689-695.

Resnekov, O., Rutberg, L. \& von Gabain, A. (1990). Changes in the stability of specific mRNA species in response to growth stage in Bacillus subtilis. Proc Natl Acad Sci U S A 87, 8355-8359.

Resnekov, O., Melin, L., Carlsson, P., Mannerlov, M., von Gabain, A. \& Hederstedt, L. (1992). Organization and regulation of the Bacillus subtilis odh $A B$ operon, which encodes two of the subenzymes of the 2-oxoglutarate dehydrogenase complex. Mol Gen Genet 234, 285-296.

Spickler, C. \& Mackie, G. A. (2000). Action of RNase II and polynucleotide phosphorylase against RNAs containing stemloops of defined structure. J Bacteriol 182, 2422-2427.

Thomas, P. S. (1980). Hybridization of denatured RNA and small DNA fragments transferred to nitrocellulose. Proc Natl Acad Sci US A 77, 5201-5205.

Tinoco, I., Jr, Borer, P. N., Dengler, B., Levin, M. D., Uhlenbeck, O. C., Crothers, D. M. \& Bralla, J. (1973). Improved estimation of secondary structure in ribonucleic acids. Nat New Biol 246, 40-41.

Vytvytska, O., Jakobsen, J. S., Balcunaite, G., Andersen, J. S., Baccarini, M. \& von Gabain, A. (1998). Host factor I, Hfq, binds to Escherichia coli ompA mRNA in a growth rate-dependent fashion and regulates its stability. Proc Natl Acad Sci US A 95, 1411814123.

Yamanaka, K., Mitta, M. \& Inouye, M. (1999). Mutation analysis of the $5^{\prime}$ untranslated region of the cold shock cspA mRNA of Escherichia coli. J Bacteriol 181, 6284-6291.

Zuker, M. (1989). On finding of all suboptimal foldings of an RNA molecule. Science 244, 48-52.

Received 30 May 2000; revised 29 August 2000; accepted 4 September 2000. 